\title{
Characterization of bladder sensory neurons in the context of myelination, receptors for pain modulators, and acute responses to bladder inflammation
}

\author{
Shelley L. Forrest ${ }^{1+}$, Peregrine B. Osborne ${ }^{1,2+}$ and Janet R. Keast ${ }^{1,2 * t}$ \\ 1 Pain Management Research Institute and Kolling Institute, University of Sydney at Royal North Shore Hospital, Sydney, NSW, Australia \\ ${ }^{2}$ Department of Anatomy and Neuroscience, University of Melbourne, Melbourne, VIC, Australia
}

Edited by:

Paul P. Bertrand, University of New South Wales, Australia

Reviewed by:

Russ Chess-Williams, Bond

University, Australia

Lu Liu, University of New South

Wales, Australia

*Correspondence:

Janet $R$. Keast, Department of

Anatomy and Neuroscience,

University of Melbourne, Medical

BIdg 181, Cnr Grattan Street and

Royal Parade, Melbourne VIC 3010,

Australia

e-mail: janet.keast@unimelb.edu.au

${ }^{\dagger}$ Present address:

Shelley L. Forrest, Department of

Pathology, University of Sydney,

Sydney, Australia;

Janet $R$. Keast and Peregrine $B$.

Osborne, Department of Anatomy

and Neuroscience, University of

Melbourne, Melbourne, Australia
Bladder sensation is mediated by lumbosacral dorsal root ganglion neurons and is essential for normal voiding and nociception. Numerous electrophysiological, structural, and molecular changes occur in these neurons following inflammation. Defining which neurons undergo these changes is critical for understanding the mechanism underlying bladder pain and dysfunction. Our first aim was to define the chemical classes of bladder sensory neurons that express receptors for the endogenous modulators of nociceptor sensitivity, glial cell line-derived neurotrophic factor (GDNF), the related neurotrophic factor, artemin, and estrogens. Bladder sensory neurons of adult female Sprague-Dawley rats were identified with retrograde tracer. Diverse groups of neurons express these receptors, and some neurons express receptors for both neurotrophic factors and estrogens. Lumbar and sacral sensory neurons showed some distinct differences in their expression profile. We also distinguished the chemical profile of myelinated and unmyelinated bladder sensory neurons. Our second aim was to identify bladder sensory neurons likely to be undergoing structural remodeling during inflammation. Following systemic administration of cyclophosphamide (CYP), its renal metabolite acrolein causes transient urothelial loss, exposing local afferent terminals to a toxic environment. CYP induced expression of the injury-related immediate-early gene product, activating transcription factor-3 (ATF-3), in a small population of sacral nitrergic bladder sensory neurons. In conclusion, we have defined the bladder sensory neurons that express receptors for GDNF, artemin and estrogens. Our study has also identified a sub-population of sacral sensory neurons that are likely to be undergoing structural remodeling during acute inflammation of the bladder. Together these results contribute to increased understanding of the neurons that are known to be involved in pain modulation and hyperreflexia during inflammation.

Keywords: dorsal root ganglion, painful bladder syndrome, pelvic pain, visceral pain, steroid, cystitis, interstitial cystitis, inflammatory pain

\section{INTRODUCTION}

Visceral pain is one of the most frequent types of pain seen in the clinical setting. It is poorly localized, associated with referred pain and is resistant to many analgesics that alleviate somatic pain. Development of appropriate animal models of visceral pain is challenging, but bladder inflammation models in rodents have revealed many changes in bladder afferent pathways and their targets in the lumbosacral spinal cord that underpin nociceptor sensitization [reviewed in De Groat and Yoshimura (2009); Daly et al. (2011); Kanai (2011)]. This sensitization is critically linked to the initiation of pain and altered reflex behaviors, including increased voiding frequency and a reduction in micturition threshold, characteristics of clinical bladder inflammation.

One of the most thoroughly characterized rodent models of bladder inflammatory pain is induced by the systemic administration of cyclophosphamide (CYP), which is then metabolized to acrolein that initiates inflammation of the lower urinary tract (Cox, 1979; Maggi et al., 1992). Following either acute or chronic CYP treatment, bladder afferent neurons undergo changes in neuropeptide and ion channel expression, leading to altered excitability and connectivity, together thought to drive spontaneous activity and increased sensitivity (Nazif et al., 2007; De Groat and Yoshimura, 2009; Kanai, 2011). Defining which particular afferent neurons undergo these changes is critical to understanding the overall mechanism underlying pain and bladder dysfunction.

Primary afferent neurons that innervate the bladder are located in dorsal root ganglia (DRG). In rats these are aggregated in spinal levels L1-L2 ("lumbar") and L6-S1 ("sacral") (Keast and De Groat, 1992). These neurons can be identified by applying retrograde tracer to the bladder in vivo, a number of days prior to removal of DRGs for analysis. Using this approach, immunohistochemical studies have determined that many of these neurons synthesize neuropeptides commonly associated with sensory and nociceptive pathways, such as calcitonin gene-related peptide (CGRP) and substance P (Vizzard, 2001; Merrill et al., 2013). Extension of these studies using double labeling fluorescence or electrophysiological recording has further 
demonstrated that many bladder afferent neurons express receptors and ion channels that function in nociception [e.g., transient receptor potential (TRP) channels] (Skryma et al., 2011; Avelino et al., 2013). Together these studies are progressively defining the functional phenotypes of bladder afferent neurons.

DRG neurons express receptors (GFR $\alpha 1-3)$ for three members of the glial cell line-derived neurotrophic factor (GDNF) family of ligands (GFL) - GDNF, neurturin, and artemin. Of these, only the artemin receptor $(\mathrm{GFR} \alpha 3)$ is associated with the peptidergic class of C-fiber neurons that is expressed by approximately half of this population (Orozco et al., 2001; Bespalov and Saarma, 2007; Ernsberger, 2008). These neurotrophic factors have powerful sensitizing actions on nociceptors and in inflamed tissue contribute to hypersensitivity and hyperalgesia (Elitt et al., 2006; Malin et al., 2006, 2011; Tanaka et al., 2011). GDNF levels in the bladder are also increased during bladder inflammation (Vizzard, 2000); to date, the levels of neurturin and artemin have not been examined here. Many sacral bladder afferent neurons express the preferred receptors for GDNF and artemin (GFR $\alpha 1$ and GFR $\alpha 3$, respectively), and these two neuron classes have distinct central projection patterns in sacral spinal cord, indicating different functions (Forrest and Keast, 2008). Following chronic bladder inflammation, the intensity of GFR $\alpha 1$ immunolabeling increases in the sacral dorsal horn, potentially due to structural remodeling (e.g., sprouting), increased receptor expression or increased trafficking of receptor to central terminals (Forrest and Keast, 2008). Together these results indicate these two neurotrophic factors may be involved in plasticity of sacral visceral afferent neurons following inflammation but do not identify which types of bladder afferents are likely to be most influenced by these factors.

The majority of bladder afferent neurons express estrogen receptors (ERs); many of these neurons are peptidergic and coexpress TRPV1 (Bennett et al., 2003). Numerous studies have implicated estrogens in pain modulation e.g., (Robbins et al., 1990, 1992; Sanoja and Cervero, 2005; Gintzler and Liu, 2012), including direct attenuation of TRPV1 responses to capsaicin $(\mathrm{Xu}$ et al., 2008). In particular, hormonal status influences bladder activity, as well as the development and severity of a number of pelvic visceral pain conditions including interstitial cystitis (Shea et al., 2000; Johnson and Berkley, 2002; Robinson and Cardozo, 2003; Dmitrieva and Berkley, 2005; Warren et al., 2011). Understanding the precise targets of estrogens in bladder sensory pathways is critical to understanding their function and potentially targeting this mechanism to modulate pain.

The first aim of this study was to define the chemical classes of lumbar and sacral bladder sensory neurons that express receptors for two types of endogenous modulators of nociceptor sensitivity, the GFLs, and estrogens. Our strategy was to use well-described markers of key functional classes of neurons, including CGRP, TRPV1 [a marker of nociceptive C-fibers (Julius and Basbaum, 2001)] and NF200 [a marker of primary afferent neurons with myelinated axons, (Lawson et al., 1993, 1997)]. An additional outcome of this group of experiments was the first immunohistochemical characterization of myelinated bladder afferent neurons that have an important role in the micturition reflex (Sengupta and Gebhart, 1994; Yoshimura et al., 2003; Fowler et al., 2008;
De Groat and Yoshimura, 2009). Our second aim was to identify and chemically characterize bladder sensory neurons that are most susceptible to the acutely altered environment of inflammation induced by CYP; this treatment is associated with acute but transient urothelial loss, potentially exposing underlying afferent terminals to the luminal environment (Birder, 2011; Birder et al., 2012). To identify neurons potentially undergoing structural change in response to this tissue damage, we visualized expression of the immediate early gene product, ATF-3 (activating transcription factor-3) in bladder afferent neurons after acute CYP treatment. ATF-3 can be induced in DRG following axotomy, application of noxious chemical stimuli and cellular stress (Hai et al., 1999; Tsujino et al., 2000; Averill et al., 2004; Shortland et al., 2006; Seijffers et al., 2007; Braz and Basbaum, 2010). Other studies have demonstrated that ATF-3 can also be up-regulated in models of joint inflammation and partial urethral obstruction (Xu et al., 2011). We therefore, investigated if acute bladder inflammation induces ATF-3 expression in DRGs and, if so, if this occurred in a particular chemical class.

\section{MATERIALS AND METHODS \\ ANIMALS}

All procedures were approved by the Animal Care and Ethics Committees of the University of Sydney and Royal North Shore Hospital, as required by the Australian Code of Practice for the Care and Use of Animals for Scientific Purposes (National Health and Medical Research Council of Australia). Adult female Sprague-Dawley rats (6-10 weeks) were used for these experiments. They were purchased from the Animal Resources Centre (Murdoch, WA, Australia), and housed under a $12 \mathrm{~h}$ light-dark cycle with free access to food and water. Estrous cycle was not monitored or controlled in these experiments.

\section{RETROGRADE TRACER INJECTIONS AND ANIMAL TREATMENTS}

To identify bladder-projecting afferent neurons in DRGs, the retrograde tracer Fluorogold (FG; Fluorochrome, Englewood, CO; $4 \%$ in sterile saline; total $<10 \mu \mathrm{l}$ ) was injected into $\sim 8$ sites in the urinary bladder base using an insulin syringe with a $30 \mathrm{G}$ needle, as described previously (Forrest and Keast, 2008). This was performed under isoflurane anaesthesia (3\% for induction, 1.5-2\% for maintenance in $\mathrm{O}_{2}$ ). Animals used only for retrograde tracing studies were perfused with fixative 7 days after surgery (see below). A second group of animals underwent retrograde tracing and 7 days later acute bladder inflammation was induced. This was performed by undergoing brief anaesthesia with isoflurane $(3 \%)$ during injection with a single dose of CYP $(75 \mathrm{mg} / \mathrm{kg}$ in sterile saline, i.p.) or saline ( $1 \mathrm{ml} / \mathrm{kg}$, i.p.), as described previously (Corrow and Vizzard, 2007). These rats were perfused with fixative $24 \mathrm{~h}$ later (see below).

\section{TISSUE PREPARATION AND IMMUNOHISTOCHEMISTRY}

Rats were heavily anaesthetised with sodium pentobarbitone ( $80 \mathrm{mg} / \mathrm{kg}$ i.p.) and transcardially perfused with $0.9 \%$ saline containing $1.25 \%$ sodium nitrite and $0.036 \%$ heparin, followed by freshly made $4 \%$ paraformaldehyde in $0.1 \mathrm{M}$ phosphate buffer (PB, pH 7.4). DRGs (L1, L2, L6, S1) and the bladder were removed and post-fixed overnight in the same fixative at $4^{\circ} \mathrm{C}$, then washed 
in $0.1 \mathrm{M}$ phosphate buffered saline (PBS, $\mathrm{pH}$ 7.2) and stored in PBS containing $0.1 \%$ sodium azide until sectioning.

DRGs were cryoprotected overnight in PBS containing 30\% sucrose and cut on a cryostat into $14 \mu \mathrm{m}$ sections. Sections were collected onto $0.1 \%$ gelatinized slides and distributed between slides so that sections stained for the same substance were sampled at least $56 \mu \mathrm{m}$ apart. Each block contained two DRGs, each from the same spinal level, and comprising one each from a saline and CYP-treated animal. Sections were air-dried, washed in PBS, and blocked for 1-2 $\mathrm{h}$ in PBS containing 10\% non-immune horse serum and $0.1 \%$ triton $\mathrm{X}-100$.

Sections were incubated overnight in combinations of antisera, washed, and incubated for $2-3 \mathrm{~h}$ in appropriate hostspecific secondaries (Table 1). Each of the primary antibodies has been characterized extensively in previous studies (Forrest and Keast, 2008; Kalous et al., 2009; Kiasalari et al., 2010) and showed general patterns of staining comparable to these earlier

Table 1 | Primary and secondary antibodies used for immunohistochemistry.

\begin{tabular}{|c|c|c|c|}
\hline Antigen & Host & Supplier/catalog number & Dilution \\
\hline \multicolumn{4}{|c|}{ PRIMARY ANTIBODIES } \\
\hline ATF-3 & Rabbit & $\begin{array}{l}\text { Santa Cruz Biotechnology } \\
\text { (Scoresby, VIC, Australia); } \\
\text { sc-188 }\end{array}$ & $1: 500$ \\
\hline ED-1 (CD86) & Mouse & $\begin{array}{l}\text { Millipore (Kilsyth, VIC, } \\
\text { Australia); MAB1435 }\end{array}$ & $1: 1000$ \\
\hline CGRP & Goat & Millipore; 1720-9007 & $1: 2000$ \\
\hline CGRP & Rabbit & $\begin{array}{l}\text { Sigma-Aldrich (Castle Hill, } \\
\text { NSW, Australia); C8198 }\end{array}$ & $1: 5000$ \\
\hline $\mathrm{ER} \alpha$ & Rabbit & $\begin{array}{l}\text { Affinity Bioreagents } \\
\text { (Scoresby, VIC, Australia); } \\
\text { PA1-308 }\end{array}$ & $1: 350$ \\
\hline $\mathrm{ER} \alpha$ & Rabbit & Millipore; C1355 & $1: 5000$ \\
\hline GFR $\alpha 1$ & Goat & $\begin{array}{l}\text { R\&D Systems (Minneapolis, } \\
\text { MN); AF560 }\end{array}$ & $1: 400$ \\
\hline GFR $\alpha 2$ & Goat & R\&D Systems; AF429 & $1: 300$ \\
\hline GFR $\alpha 3$ & Goat & R\&D Systems; AF2645 & $1: 300$ \\
\hline NF200 & Mouse & Sigma-Aldrich; N0142 & $1: 4000$ \\
\hline NOS & Rabbit & $\begin{array}{l}\text { Zymed Laboratories (now } \\
\text { Invitrogen, Mulgrave, VIC, } \\
\text { Australia); } 61-7000\end{array}$ & $1: 500$ \\
\hline TRPV1 & Guinea pig & Millipore; AB5566 & $1: 5000$ \\
\hline TRPV1 & Rabbit & $\begin{array}{l}\text { Neuromics (Burwood East, } \\
\text { VIC, Australia); RA10110 }\end{array}$ & $1: 8000$ \\
\hline \multicolumn{4}{|c|}{ SECONDARY ANTIBODIES } \\
\hline anti-goat Cy3 & Donkey & $\begin{array}{l}\text { Jackson Laboratories; } \\
\text { 705-165-147 }\end{array}$ & 1:1000 \\
\hline anti-guinea pig FITC & Donkey & $\begin{array}{l}\text { Jackson Laboratories; } \\
\text { 706-095-148 }\end{array}$ & $1: 100$ \\
\hline anti-mouse AF488 & Donkey & Invitrogen; A-21202 & $1: 1000$ \\
\hline anti-mouse $\mathrm{Cy} 3$ & Donkey & $\begin{array}{l}\text { Jackson Laboratories; } \\
\text { 715-165-150 }\end{array}$ & $1: 2000$ \\
\hline anti-rabbit AF488 & Donkey & Invitrogen; A21206 & $1: 2000$ \\
\hline anti-sheep AF488 & Donkey & Invitrogen; A-11015 & 1:1000 \\
\hline
\end{tabular}

reports. To identify neurons that could potentially be influenced by GFLs, we used antibodies raised against the preferred receptors for GDNF (GFR $\alpha 1)$, neurturin $(\mathrm{GFR} \alpha 2)$, and artemin $(\mathrm{GFR} \alpha 3)$. In this study, we utilized two different ER $\alpha$ antibodies, the first purchased from Affinity Bioreagents has been used previously by our laboratory (Bennett et al., 2003), and the second from Millipore that has been reported to label a different population of neurons (Kiasalari et al., 2010). Here we have distinguished these two $\mathrm{ER} \alpha$ antibodies by their manufacturer, i.e., $\mathrm{ER} \alpha$ (Affinity) and $\mathrm{ER} \alpha$ (Millipore). The antibody from Affinity was raised against the $\mathrm{N}$-terminal 21 residues of the receptor, whereas the antibody from Millipore was raised against the C-terminal 15 residues. According to information supplied by the manufacturers, specificity has been demonstrated with Western blotting, notably that neither ER $\alpha$ antibody crossreacts with the most likely potential cross-reacting receptor, ER $\beta$. We have previously determined that all ER $\alpha$ immunolabeled in rat DRG with the ER $\alpha$ (Affinity) antibody is absorbed by the antigenic peptide, including in neurons that also express ER $\beta$; (Bennett et al., 2003) data provided by Kiasalari et al. (2010) on the $\mathrm{ER} \alpha$ (Millipore) antibody, has shown patterns of staining comparable to those demonstrated by that group with in situ hybridization.

Antibodies were diluted with 0.1 M hypertonic PBS ( $\mathrm{pH} 7.2$ ). All incubations were performed in a humid chamber, in the dark at room temperature. Slides were cover-slipped with carbonatebuffered glycerol ( $\mathrm{pH}$ 8.6).

To confirm acute bladder inflammation, bladder sections $(14 \mu \mathrm{m})$ from acute CYP-treated animals and controls were processed for ED-1, as described for DRG sections. Qualitative assessment showed a pronounced infiltration of ED-1-positive cells (likely monocytes and macrophages) in the detrusor and mucosa of acute CYP-treated animals but not in the saline group (not shown).

\section{QUANTITATION OF NEURONAL POPULATIONS}

DRGs were viewed under an Olympus BX51 fluorescence microscope (Olympus Australia, Melbourne, Australia) and counts made while viewing directly from the microscope. To characterize bladder-projecting neurons, a minimum of 120 nucleated profiles of FG-labeled neurons were counted from five sections from each ganglion. Ganglia were classified as "lumbar" if from spinal levels L1 or L2 and "sacral" if from L6 and S1. These neurons were classified on the basis of their immunoreactivity (IR) for GFRs, TRPV1, CGRP, ER $\alpha$ (both antibodies), NF200 and NOS. The percentage of FG neurons expressing each marker or co-marker was averaged for each DRG in each rat. The arcsinetransformed data from sacral and lumbar DRGs was compared using a paired $t$-test. The number of ATF-3 positive FG-labeled neurons containing CGRP, NOS, and the GFRs following acute CYP treatment or saline were compared by performing Tukey's multiple comparison post hoc test on arcsine transformed data. This was used to detect an effect of CYP treatment on the proportion of FG-labeled neurons expressing each of these markers and a comparison between sacral and lumbar DRGs. In past studies, sacral DRGs have been more thoroughly characterized so will be the primary point of reference and data on these neurons will be 
provided first in each of the histograms and in the text. All results are provided as the mean \pm s.e.m. and $P<0.05$ was regarded as statistically significant.

\section{FIGURE PRODUCTION}

Eight-bit monochrome images were captured with an RT-SPOT camera (Diagnostic Instruments, Sterling Heights, MI) and digitized using Image Pro Plus (Media Cybernetics, Silver Spring, $\mathrm{MD})$. For figure production, only minor adjustments were made to brightness and contrast in Adobe Photoshop (San Jose, CA) to best represent the staining as viewed directly under the microscope. Colorized images were produced by pasting monochrome images into the appropriate color channel of a 24-bit RGB file in Photoshop; these images were collated and labeled using InDesign (Adobe Creative Suite 5). FluoroGold labeling was colorized blue instead of its native color to facilitate viewing of merged images.

\section{RESULTS \\ GFR $\alpha 1$ AND GFR $\alpha 3$ WERE EXPRESSED IN MANY TRPV1-IR BLADDER-PROJECTING NEURONS}

FG-labeled neurons were identified in all of the ganglia and we first quantified how many of these neurons were immunoreactive for each of CGRP, the GFRs, and TRPV1. TRPV1 is a marker of polymodal nociceptor neurons that is expressed by the majority of bladder afferent neurons (Bennett et al., 2003). Previous studies of DRGs at other spinal levels have shown that the majority of CGRP-IR neurons express TRPV1 (Kiasalari et al., 2010) and that GFR $\alpha 3$-IR is expressed in a sub-population of CGRP-IR neurons (Orozco et al., 2001; Kalous et al., 2009). From these previous studies we also predicted that GFR $\alpha 1$ - and GFR $\alpha 2$-IR would be found in the non-peptidergic population (Bennett et al., 1998; Kalous et al., 2007, 2009).

In sacral DRG, $70.6 \pm 3.1 \%$ of FG-labeled neurons contained TRPV1-IR and $54.2 \pm 2.5 \%$ contained CGRP-IR $(n=$ 4, Figures 1A,D,E). Expression of each GFR in retrogradely labeled neurons varied with the type of receptor, with $20.4 \pm$ $1.4 \%$ GFR $\alpha 1-I R,<2 \%$ GFR $\alpha 2-I R$ and $34.3 \pm 3.0 \%$ GFR $\alpha 3-$ IR ( $n=4$, Figures 1A,F-H). Quantification of FG-labeled neurons in lumbar DRG found broadly similar patterns of labeling ( $n=4$; Figure 1A), although consistent with previous publications (Bennett et al., 2003), we found CGRP-IR neurons more prevalent in lumbar than sacral DRGs $(67.7 \pm 1.8 \%$ lumbar vs. $54.2 \pm 2.5 \%$ sacral, $n=4, P<0.001$, Figure 1A).

We next investigated the co-expression of GFR $\alpha 1-$, GFR $\alpha 3-$, and CGRP-IR with TRPV1-IR in bladder afferent neurons (Figures 1B,C,I,J). This was not performed with GFR $\alpha 2$ as it was expressed by so few FG-positive neurons. At both spinal levels, approximately one third of GFR $\alpha 1$-IR bladder afferent neurons contained TRPV1-IR (Figure 1B), but these comprised only $\sim 10 \%$ of all TRPV1-IR bladder afferent neurons (Figure 1C). Almost all GFR $\alpha 3$ - and CGRP-IR neurons contained TRPV1-IR (Figures 1B,I,J). Conversely, approximately half of all TRPV1-IR bladder neurons contained GFR $\alpha 3$-IR (Figures 1C,I) and $70-80 \%$ contained CGRP-IR (Figures 1C,J). In both sacral and lumbar DRGs, almost all GFR $\alpha 3$-IR bladder neurons contained CGRP-IR (sacral, $94.3 \pm 2.1 \%$; lumbar, $96.7 \pm 1.4 \%$; $n=4)$ and the majority of CGRP-IR bladder neurons were GFR $\alpha 3$-IR (sacral, 70.1 $\pm 2.8 \%$; lumbar, $61.2 \pm 2.3 \%, n=4$ ).

\section{ER $\alpha$ WAS EXPRESSED IN FUNCTIONALLY DIVERSE POPULATIONS OF BLADDER SENSORY NEURONS}

DRG sections immunostained with either ER $\alpha$ antibody labeled the nucleus of a subpopulation of neurons; neurons with a nucleus brighter than the cytoplasm were regarded as ER $\alpha$-IR. In some neurons stained with the Affinity antibody, in addition to $\mathrm{ER} \alpha$-positive nuclei there was weak cytoplasmic staining. Assessment of FG-labeled neurons labeled with this antibody showed that in sacral and lumbar DRGs, $29.6 \pm 3.9 \%$ and $39.4 \pm 1.2 \%$, respectively, were immunoreactive for $\mathrm{ER} \alpha(n=$ 5 , Figures 2A,B). In these double-stained sections, we found a similar pattern of expression for GFRs and TRPV1 (Figure 2B) as described above. However, in this component of the study we also co-stained for the myelination marker, NF200, and found that $\sim 60 \%$ of sacral and lumbar FG-labeled neurons were immunoreactive for NF200 ( $n=5$, Figures 2A,B).

Using the antibody from Affinity, ER $\alpha$-IR neurons were then categorized according to their co-expression with GFR $\alpha 1, \mathrm{GFR} \alpha 3$, CGRP, TRPV1, and NF200 (Figures 2C-F). Approximately 40\% of GFR $\alpha 1-I R$ FG-labeled neurons in sacral and lumbar DRGs contained ER $\alpha-I R$, and these comprised $\sim 30 \%$ of all ER $\alpha$-IR neurons. However, a difference between bladder sensory neurons in the sacral and lumbar DRG was revealed with GFR $\alpha 3$ co-labeling-very few sacral GFR $\alpha 3$-IR neurons were ER $\alpha$-IR, compared to $\sim 20 \%$ of these neurons being $\mathrm{ER} \alpha$-IR in lumbar DRG $(n=5, P=0.01)$. This difference was also reflected in the proportion of ER $\alpha$-IR neurons containing GFR $\alpha 3$-IR (5.8 \pm $2.3 \%$ sacral vs. $27.3 \pm 3.6 \%$ lumbar; $n=5, P<0.001)$. Using this same antibody purchased from Affinity, the co-expression of ER $\alpha$ with TRPV1 and CGRP has previously been reported in bladder sensory neurons (Bennett et al., 2003). The current study using this antibody showed similar results, with $20-30 \%$ of all CGRP- and TRPV1-IR bladder sensory neurons in lumbar and sacral DRG showing ER $\alpha$-IR. Conversely, 30\% of ER $\alpha$-IR bladder sensory neurons contained CGRP-IR and half contained TRPV1-IR.

The expression of ER $\alpha$ has not previously been compared between myelinated and unmyelinated bladder sensory neurons. Using the same $\mathrm{ER} \alpha$ antibody as above (from Affinity) and immunoreactivity for NF200 to indicate myelination, we found that in sacral DRGs only $\sim 25 \%$ of myelinated bladder neurons were labeled for ER $\alpha$-IR; even fewer $(\sim 15 \%)$ of this population expressed ER $\alpha$ in lumbar DRGs (Figures 2C,D; $P=0.03, n=5$ ). When viewing the co-expression from the perspective of the ER $\alpha$ positive population of bladder sensory neurons, in sacral DRG around half of these were myelinated and potentially fewer of these were myelinated in lumbar DRG (although this did not quite reach statistical significance; $P=0.05, n=5$ ).

The ER $\alpha$ antibody obtained from Millipore produced a similar pattern of IR in the nucleus of DRG neurons as that obtained by Affinity, however, the Millipore antibody labeled fewer bladder afferent neurons. As a proportion of FG-labeled neurons, the Millipore antibody labeled $17.9 \pm 1.8 \%$ (sacral) and $13.5 \pm 1.5 \%$ (lumbar) of FG neurons, whereas the Affinity antibody labeled 

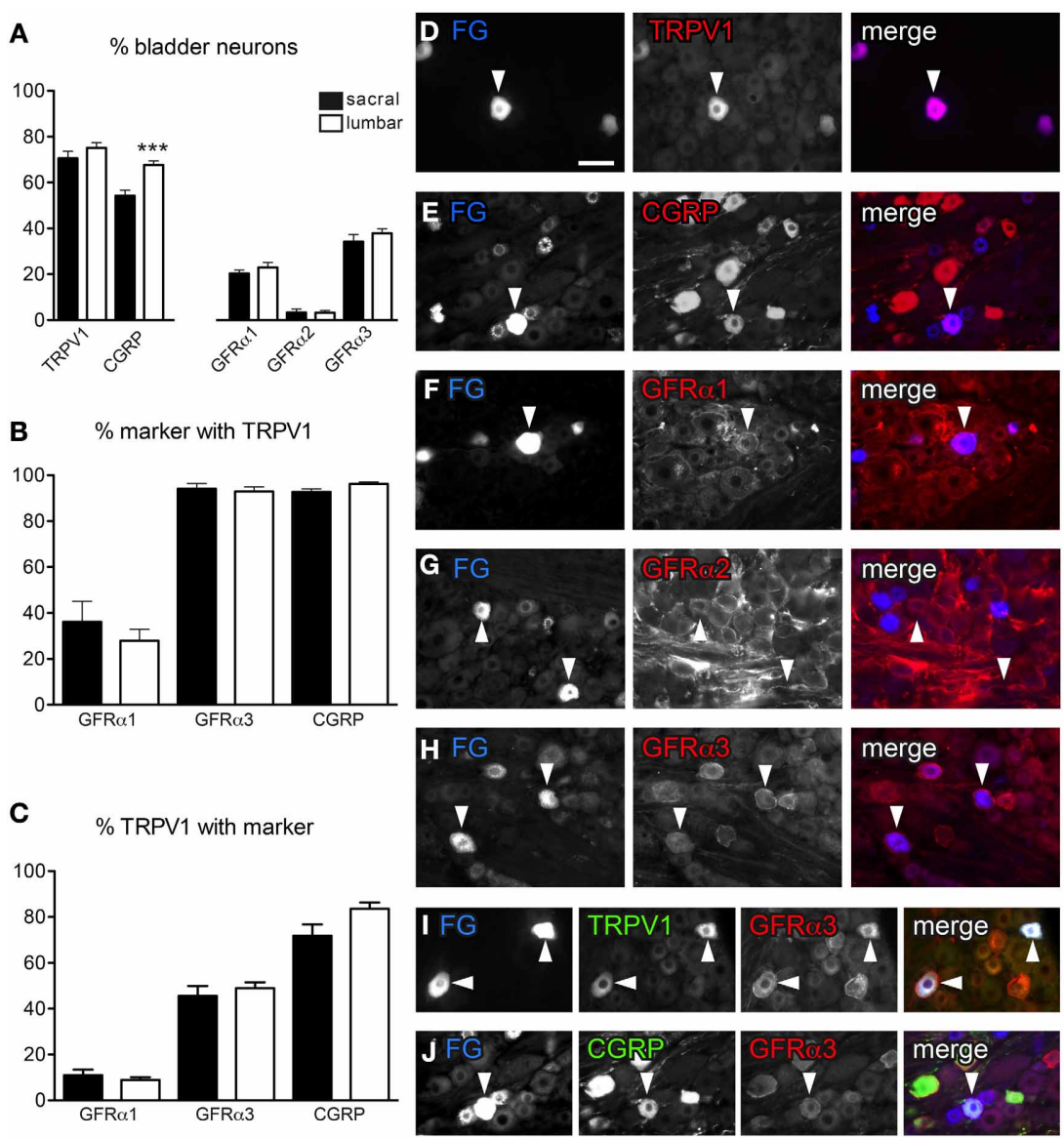

FIGURE 1 | Distribution of TRPV1-, CGRP-, and GFR $\alpha$-immunoreactivity (IR) in bladder sensory neurons. (A) The proportion of bladder sensory neurons containing TRPV1-, CGRP-, and GFR-(IR) at each spinal level. Bladder-projecting neurons were identified with the retrograde tracer, FluoroGold (FG). A higher proportion of FG-labeled neurons contain CGRP-IR in lumbar than sacral DRGs $\left({ }^{* * *} P<0.001\right)$. (B) The proportion of GFR $\alpha 1-$, GFR $\alpha 3$-, and CGRP-IR bladder sensory neurons co-expressing TRPV1-IR. (C) The proportion of TRPV1-IR bladder sensory neurons co-expressing GFR $\alpha 1$, GFR $\alpha 3-$, or CGRP-IR. (D-J): Each row of micrographs comprises images from the same field, showing immunostaining for one or more markers in retrogradely-labeled bladder sensory neurons. The first panel shows the tracer dye, FluoroGold (FG), the second panel shows an immunolabel and the last panel provides a merged, colorized image. The color of each label in the merged image is indicated by the color of the text in the relevant monochrome image. (D-H) Example of FG neurons expressing TRPV1- (D), CGRP- (E), GFR $\alpha 1-(\mathbf{F})$, and GFR $\alpha 3-I R(\mathbf{H})$. Very few FG neurons were labeled for GFR $\alpha 2$ (G). (I, J) Co-expression of GFR $\alpha 3$ with TRPV1 (I) and CGRP (J) in FG-labeled bladder-projecting neurons. Histograms show the mean \pm s.e.m. $(n=4)$, analyzed by a paired $t$-test on arcsine-transformed data. Scale bar in panel (D) represents $50 \mu \mathrm{m}$ and applies to all micrographs. Arrowheads indicate examples of retrogradely labeled neurons and their relative location in matching panels.
$29.6 \pm 3.9 \%$ (sacral) and $39.4 \pm 1.2 \%$ (lumbar) of bladder neurons (all $n=5$ ). We then wished to determine if this decrease was due to a failure of the Millipore antibody to stain a particular population of neurons labeled as $\mathrm{ER} \alpha$ by the Affinity antibody; if so, this could reveal a difference in specificity for a form of the receptor that is distributed differently between neuronal classes.

These additional studies showed that, in contrast to the Affinity antibody, the Millipore antibody failed to label ER $\alpha$ in peptidergic bladder sensory neurons. It was rare to find bladder sensory neurons that co-expressed ER $\alpha$ with GFR $\alpha 3$ - or CGRPIR in either lumbar or sacral DRG. However, using the Millipore antibody, co-expression with GFR $\alpha 1$ in sacral bladder sensory neurons was observed to a similar degree as with the antibody purchased from Affinity. Specifically, at this spinal level 25\% GFR $\alpha 1$-IR bladder sensory neurons contained ER $\alpha$-IR, and these comprised approximately half of all ER $\alpha$-IR neurons. Lumbar bladder sensory neurons showed less expression of ER $\alpha$ using the Millipore antibody, with only $\sim 5 \%$ of GFR $\alpha 1$-IR neurons containing ER $\alpha$-IR, and these comprising $\sim 10 \%$ of all ER $\alpha$-IR neurons. Further examination of the labeling obtained with these two antibodies was performed in the context of myelination status (see below).

\section{CHARACTERIZATION OF MYELINATED BLADDER AFFERENT NEURONS}

Previous studies have reported that just over half of all bladder afferent neurons express the myelination marker, NF200-IR (Hayashi et al., 2009), but its distribution in different chemical classes is unknown. NF200 antibody labeled many DRG neurons with varying intensity, with the largest diameter labeled neurons having the brightest staining (Figures 3A,B). Many NF200-IR 


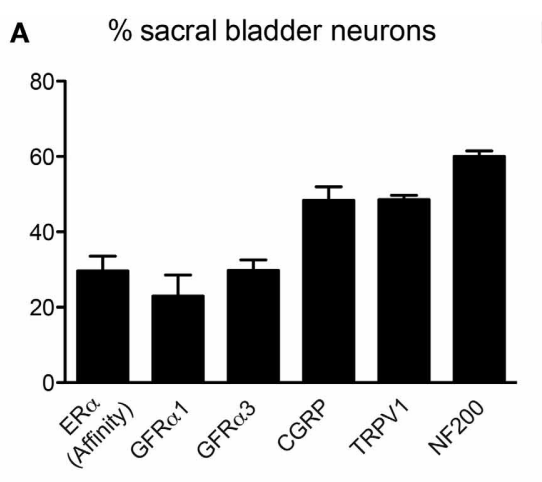

B \% lumbar bladder neurons

C $\%$ marker with $\mathrm{ER} \alpha$ (Affinity)
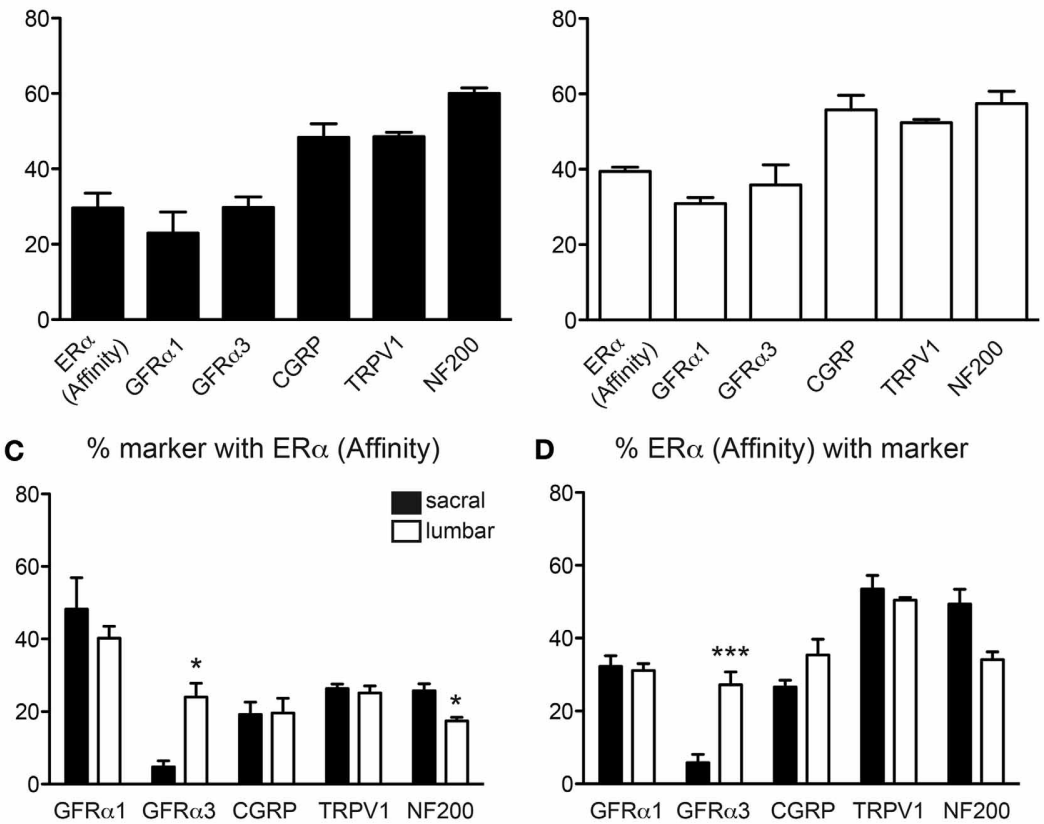

D $\% E R \alpha$ (Affinity) with marker
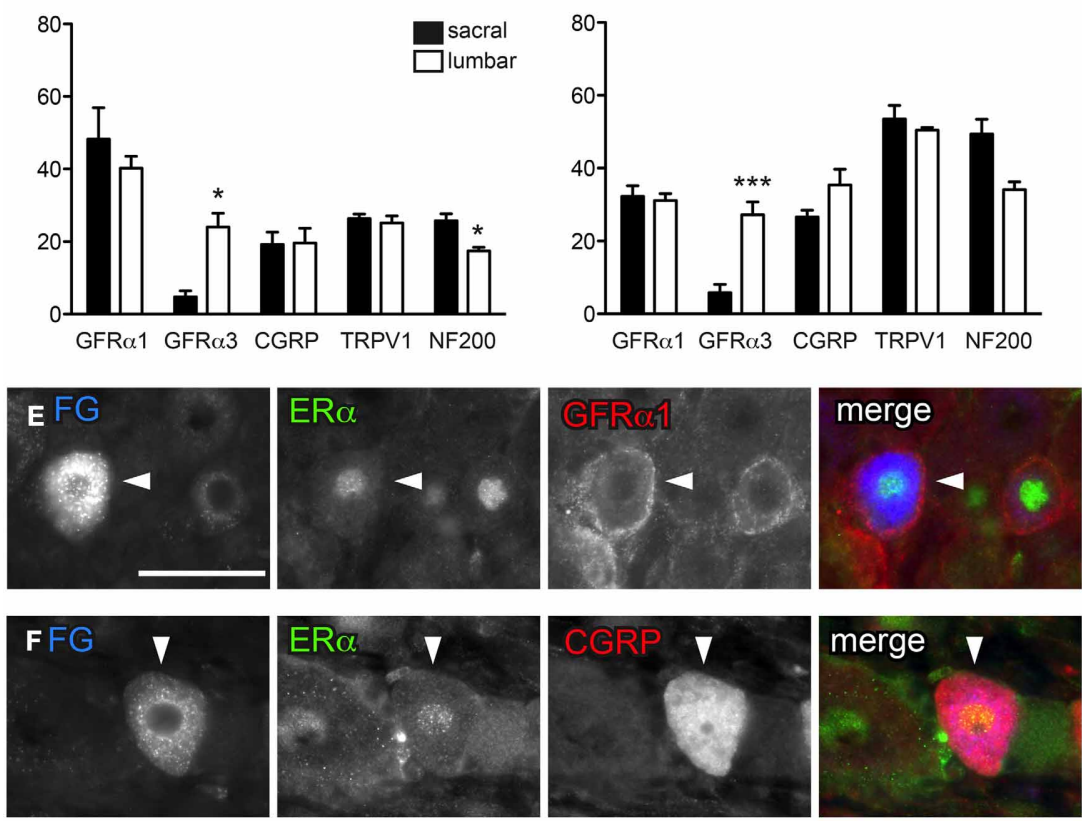

FIGURE 2 | Distribution of ER $\alpha$ and GFRs in bladder sensory neurons. This figure illustrates immunostaining for $E R \alpha$ using the antibody purchased from Affinity Bioreagents. (A, B) The proportion of sacral (A) and lumbar (B) bladder-projecting neurons containing ER $\alpha-$, GFR $\alpha 1$, GFR $\alpha 3-$, CGRP-, TRPV1-, and NF200-immunoreactivity (IR). (C) The proportion of GFR $\alpha 1$-, GFR $\alpha 3$ CGRP-, TRPV1-, and NF200-IR bladder sensory neurons containing ER $\alpha-I R$. A higher proportion of GFR $\alpha 3-I R$ neurons contained $E R \alpha-I R$ in lumbar vs. sacral DRGs $(* P=0.01)$, whereas a higher proportion of NF200-IR neurons contained $E R \alpha-I R$ in sacral vs. lumbar DRGS $(* P=0.03)$. (D) The proportion of $E R \alpha-I R$ bladder sensory neurons containing each marker. A higher proportion of ER $\alpha-I R$ neurons contained GFR $\alpha 3-I R$ in lumbar vs. sacral DRGs $\left({ }^{* * *} P<0.001\right)$. Data represents the mean \pm s.e.m. $(n=5)$, analyzed by a paired $t$-test on arcsine-transformed data. (E) Co-expression of ER $\alpha$ - and GFR $\alpha 1$-IR in a FluoroGold (FG)-labeled neuron. (F) Co-expression of ER $\alpha$ - and CGRP-IR in a FG-labeled neuron. Images are shown as monochrome image sets and the merged colorized image. The color of each label in the merged image is indicated by the color of the text in the relevant monochrome image. Scale bar in panel (E) represents $50 \mu \mathrm{m}$ and applies to all images.

Arrowheads indicate examples of retrogradely labeled neurons and their relative location in matching panels. axons were also observed running through the DRG. Consistent with previous reports (Hayashi et al., 2009), we found just over half of all sacral and lumbar bladder-projecting neurons contained NF200-IR ( $54.8 \pm 1.6 \%$ sacral; $57.3 \pm 1.4 \%$ lumbar, $n=3)$.

We then performed double-labeling studies to determine if myelinated bladder sensory neurons express nitric oxide synthase (NOS), CGRP, GFR $\alpha 1$, or ER $\alpha$ (using both sources of $\mathrm{ER} \alpha$ antisera). Assessment of FG-labeled neurons in sacral and lumbar DRG for the other neuronal classes (CGRP, GFR $\alpha 1$, and $E R \alpha$ ) showed that each class comprised both myelinated (NF200-IR) and unmyelinated (NF200-negative) neurons, however, their relative distributions between these populations differed (Figures 3C,D). When all populations of myelinated neurons were analyzed separately they totaled more than $100 \%$ (Figure 3D), as would be expected given that many neurons will actually express more than one of these substances (e.g., $\mathrm{ER} \alpha$ with CGRP).

NOS activity has been linked to plasticity of visceral afferent pathways and is expressed in some bladder afferent neurons (Vizzard et al., 1995a,b, 1996; Callsen-Cencic and Mense, 1997). NOS-IR was of variable labeling intensity and localized 

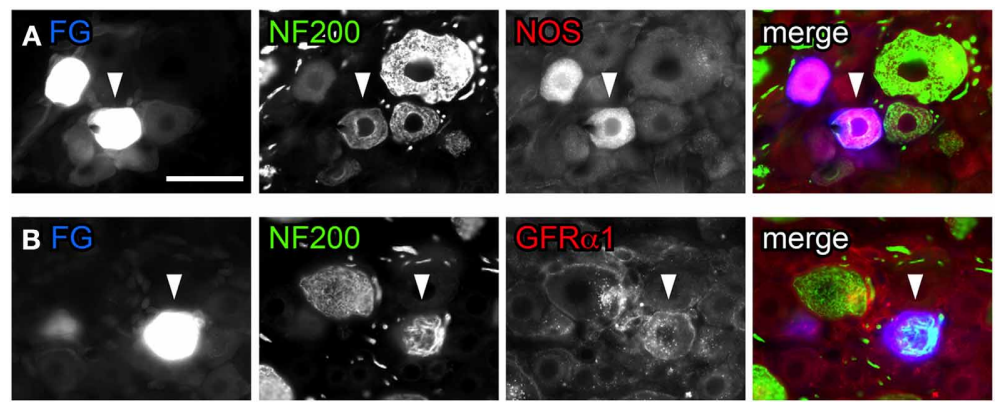

C

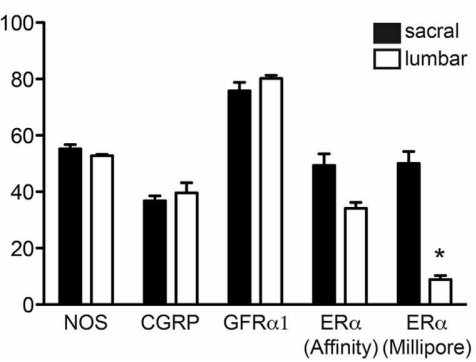

FIGURE 3 | Distribution of NF200-immunoreactivity (IR) in bladder sensory neurons. Data shown here compares two antibodies raised against $E R \alpha$, purchased from either Affinity Bioreagents or Millipore. (A, B) Co-expression of NF200 with $\operatorname{NOS}(\mathbf{A})$ and GFR 1 (B) in bladder-projecting neurons retrogradely labeled with FluoroGold (FG). The neurons in panel (B) are from the same field of view as Figure 1F. Images are shown as monochrome image sets and the merged image. The color of each label in the merged image is indicated by the color of the text in the relevant monochrome image. Scale bar in panel (A) represents $50 \mu \mathrm{m}$ and applies to all images. (C) The proportion of NOS-,

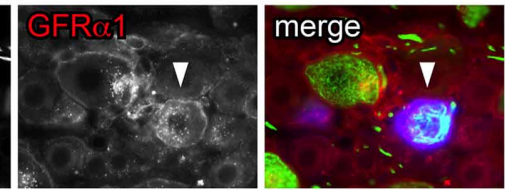

D

\% NF200 with marker

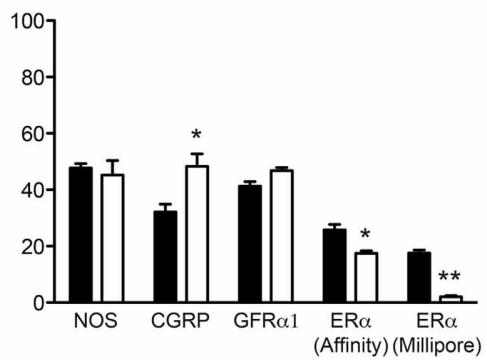

CGRP-, GFR $\alpha 1-$, and ER $\alpha-$ IR bladder-projecting neurons containing NF200-IR. Using the Millipore antibody, a higher proportion of ER $\alpha-I R$ neurons contain NF200-IR in sacral than lumbar DRGs (* $P=0.02$ ). (D) The proportion of NF200-IR bladder afferent neurons containing each marker. A higher proportion of NF200-IR neurons contain CGRP-IR in lumbar than sacral DRGs $\left({ }^{*} P=0.02\right)$. Using either $\mathrm{ER} \alpha$ antibody, a higher proportion of NF200-IR bladder afferent neurons contain ER $\alpha$ in sacral compared to lumbar DRGs $\left(* P=0.03\right.$ for ER $\alpha$ [Affinity], ${ }^{* *} P<0.01$ for $\mathrm{ER} \alpha$ [Millipore]). Data represents the mean \pm s.e.m. $(n=5)$, analyzed by a paired $t$-test on arcsine-transformed data. to medium sized neurons. About half of all bladder neurons contained NOS-IR (sacral, $45.9 \pm 1.5 \%$; lumbar, $46.6 \pm 3.1 \%$; Figure 3A, $n=3$ ). This is a much higher basal expression of NOS than reported previously (Vizzard et al., 1995a,b, 1996; CallsenCencic and Mense, 1997) and may reflect differences between antisera or in the level of labeling intensity that was regarded as positive. Just over half of all NOS-IR bladder neurons contained NF200-IR and, in turn, these comprised almost half of all NF200IR neurons (Figures 3A,C,D); this did not vary between lumbar and sacral DRG.

At each spinal level, $\sim 40 \%$ of CGRP-IR bladder neurons were NF200-IR (Figure 3C), however, more of these NF200-IR neurons expressed CGRP in the lumbar than the sacral DRG $(48.3 \pm 4.4 \%$ lumbar vs. $32.1 \pm 2.0 \%$ sacral; Figure $3 D, P=$ $0.02, n=3$ ). Approximately $80 \%$ of GFR $\alpha 1$-IR bladder neurons contained NF200-IR and these comprised $\sim 40 \%$ of all NF200IR bladder neurons (Figures 3B-D); this did not vary between lumbar and sacral DRG.

Expression of $\mathrm{ER} \alpha$ relative to myelination status was more complex, showing differences between spinal levels and between the two ER $\alpha$ antibodies (Figures 3C,D). Using the antibody from Affinity, the proportion of ER $\alpha$-IR bladder neurons containing NF200-IR may have been higher in sacral than lumbar DRGs; this was close to reaching statistical significance $(n=5, P=0.05)$.
In line with this observation, a higher proportion of NF200IR bladder neurons contained ER $\alpha$-IR in sacral than lumbar DRGs $(n=5, P=0.03)$. Although the $\mathrm{ER} \alpha$ antibody obtained from Millipore labeled a smaller proportion of neurons than the Affinity antibody, similar patterns of co-expression were observed relative to NF200. That is, a higher proportion of ER $\alpha$-IR bladder neurons contained NF200-IR in sacral DRGs compared to lumbar DRGs $(n=5, P=0.02)$. A higher proportion of NF200IR neurons also contained ER $\alpha$-IR in sacral than lumbar DRG $(P=0.02, n=5)$.

\section{ACUTE BLADDER INFLAMMATION INDUCED ATF-3 ACTIVATION AND INCREASED NOS EXPRESSION IN SACRAL BLADDER AFFERENT NEURONS}

FG-labeled neurons were assessed for presence of the transcription factor, ATF-3. Following acute CYP treatment there was a small, but significant induction of ATF-3 in bladder neurons in sacral DRG (Figure 4A; $P=0.03, n=3$ ). ATF-3 neurons were rarely seen in DRG from saline treated animals. We also observed an increase in the number of neurons expressing NOSIR (Figure 4B; $P=0.01 ; n=3$ ) compared to control animals, but there was no effect of CYP on the proportion of bladder sensory neurons labeled for CGRP, GFR $\alpha 1$, or GFR $\alpha 3$ (Figure 4B). Co-expression studies revealed that $\sim 80 \%$ of ATF- 3 nuclei were 


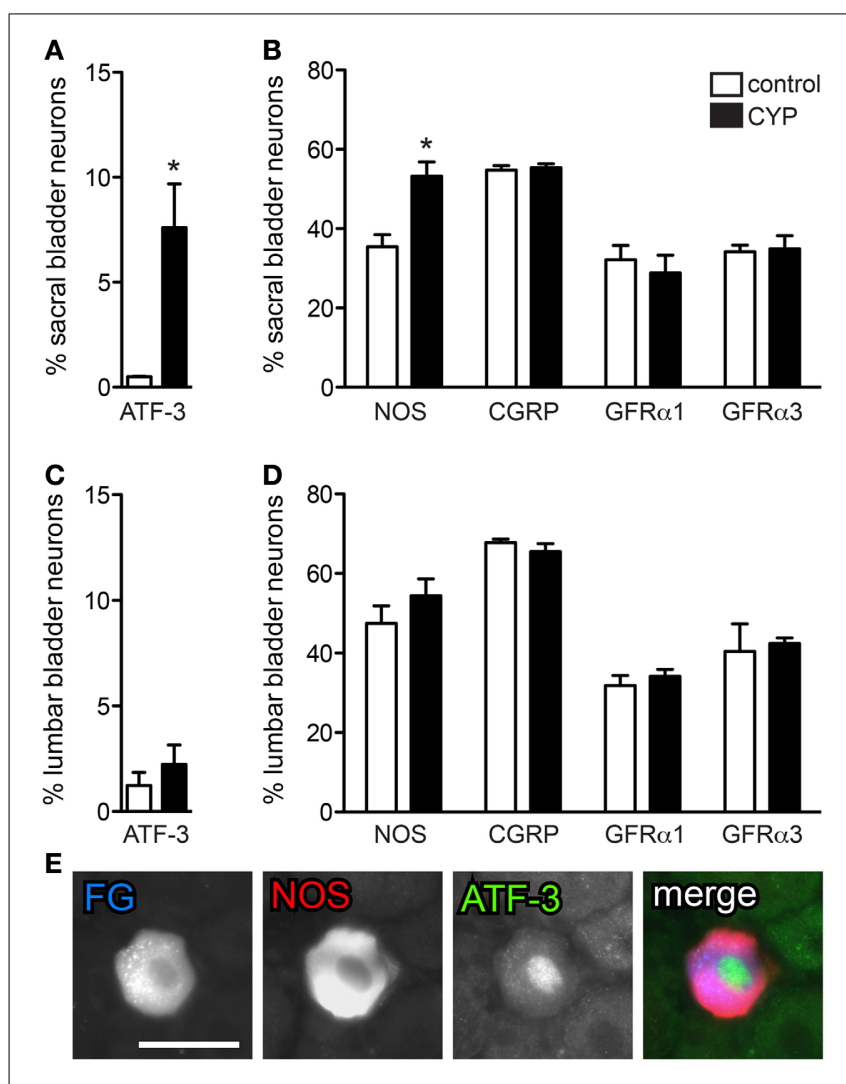

FIGURE 4 | Acute bladder inflammation induced ATF-3 and increased NOS-IR in sacral bladder sensory neurons. (A) Acute cyclophosphamide (CYP) treatment caused a small, but significant induction of ATF-3 in sacral bladder sensory neurons ( ${ }^{*} P=0.03$ ). (B) In sacral DRG, acute CYP treatment increased the proportion of FG-labeled neurons containing NOS-IR ( ${ }^{*} P=0.01$ ) but did not affect the prevalence of CGRP-, GFR $\alpha 1$-, or GFR $\alpha 3-$ IR bladder sensory neurons. (C) In lumbar DRG, CYP treatment did not affect the proportion of lumbar bladder sensory neurons containing ATF-3. (D) Acute CYP treatment did not affect the proportion of lumbar bladder sensory neurons with NOS-, CGRP-, GFR $\alpha 1$-, or GFR $\alpha 3-I R$. (E) Approximately $80 \%$ of ATF-3-IR nuclei were found in NOS-IR neurons. Data represents the mean \pm s.e.m. $(n=3)$, analyzed by a paired $t$-test on arcsine-transformed data. Images are shown as monochrome image pairs and the merged image. The color of each label in the merged image is indicated by the color of the text in the relevant monochrome image. Scale bar in the first panel (left) represents $30 \mu \mathrm{m}$ and applies to all images.

found in NOS-IR neurons (Figure 4E). In contrast to sacral bladder afferent neurons, acute CYP treatment had no effect on the expression of ATF-3, NOS-, CGRP-, GFR $\alpha 1$-, or GFR $\alpha 3-$ IR in lumbar FG-labeled neurons (Figures 4C,D).

\section{DISCUSSION}

This is the first study to identify the populations of bladder sensory neurons in lumbar and sacral DRG that express receptors for the GDNF family of neurotrophic factors and estrogens, and are potentially influenced by these endogenous modulators of nociception. The results demonstrated that diverse but not identical groups of neurons express these receptors and some bladder sensory neurons express both families of receptors. Lumbar and sacral sensory neurons showed some distinct differences in their labeling profiles. We also identified a small population of bladder sensory neurons in sacral DRG that upregulate the injury-related transcription factor, ATF-3, following acute systemic administration of CYP. We propose that these are the neurons most likely to be damaged and undergoing structural remodeling during inflammation. This remodeling may drive the development of abnormal behavior (spontaneous activity, sensitization) in the chronic setting.

It has previously been shown that populations of bladder sensory neurons express receptors for GDNF and artemin (i.e., GFR $\alpha 1$ and GFR $\alpha 3$, respectively) (Forrest and Keast, 2008). The central projections of sacral sensory neurons expressing these receptors terminate in different locations within the dorsal horn of the spinal cord, illustrating their distinct roles within micturition (and potentially nociceptive) circuitry (Forrest and Keast, 2008). By performing double-labeling immunofluorescence, we have shown that, similar to DRGs from other spinal levels, these two receptors are associated with different populations of neurons-GFR $\alpha 1$ with non-peptidergic and GFR $\alpha 3$ with peptidergic neurons (Bennett et al., 1998, 2000; Orozco et al., 2001). Therefore, if levels of GDNF or artemin increase in disease states such as chronic inflammation, they would be predicted to influence different aspects of bladder function. Moreover, GFR $\alpha 3$ positive are peptidergic so also express the nerve growth factor receptor, trkA (Averill et al., 1995), increasing the complexity of possible mechanisms for their peripheral sensitization (Pezet and Mcmahon, 2006).

Both groups of bladder sensory neurons (GFR $\alpha 1$ - and GFR $\alpha 3$ IR) include neurons that could be considered nociceptive by their expression of TRPV1. These comprise a minority of the GFR $\alpha 1$-IR bladder afferents and the majority of GFR $\alpha 3$-IR bladder afferents. None of the bladder afferents label for the receptor of the related neurotrophic factor, neurturin, although many pelvic autonomic neurons (including bladder motor neurons) express this receptor (Laurikainen et al., 2000; Wanigasekara et al., 2004; Wanigasekara and Keast, 2005). It is not known if GFR $\alpha 2$ is expressed by sensory neurons innervating other pelvic viscera, although there is functional evidence for its presence in other populations of afferents (Stucky et al., 2002; Lindfors et al., 2006; Malin et al., 2006). TRPV1 is generally considered a marker of polymodal nociceptors (Julius and Basbaum, 2001) but many TRPV1-IR visceral afferent neurons are not exclusively involved in nociception and are likely to play a role in normal autonomic regulation, including the micturition reflex (De Groat and Yoshimura, 2001, 2009; Robinson and Gebhart, 2008). For example, intravesical injection of capsaicin into the bladder decreases the micturition threshold and induces bladder contraction (Maggi, 1992; Dmitrieva et al., 1997). Some bladder neurons develop a nociceptive function under inflammatory conditions (Bjorling et al., 2003; Nazif et al., 2007). At other spinal levels, GDNF and artemin contribute to nociceptor sensitization and hyperalgesia (Elitt et al., 2006; Malin et al., 2006, 2011). Artemin is also likely to contribute to the development and maintenance of colorectal hypersensitivity (Tanaka et al., 2011). GDNF levels in the bladder are increased during bladder inflammation (Vizzard, 2000) but the expression of artemin by the rat bladder is unknown. Together these results indicate that GDNF and 
artemin may be involved in the sensitization and plasticity of pelvic visceral pathways.

Many bladder afferent neurons express ERs (Bennett et al., 2003) and various actions of estrogens have been reported on these neurons. Estrogens have complex actions on bladder afferent neurons where they modulate two signaling pathways involved in neural plasticity and nociceptor sensitization, p38 and extracellular signal-related (ERK) mitogen-activated protein (MAP) kinase (Cheng and Keast, 2009). Another study (Xu et al., 2008) has shown that estradiol acts directly on DRG neurons to reduce TRPV1 activation by capsaicin and suggested that pain could be influenced by modulation of ERs in DRG neurons. Here we used two different antibodies, one of which (Affinity Bioreagents) has been used previously by our laboratory to identify ER $\alpha$ in bladder sensory neurons in rats (Bennett et al., 2003), and a second from Millipore that has recently been described in a study of perineal afferents (Kiasalari et al., 2010). It has been demonstrated previously that many peptidergic and TRPV1-IR bladder sensory neurons express ERs (Bennett et al., 2003). In the current work using the Affinity antibody, we showed that these receptors were also expressed by some non-peptidergic, GFR $\alpha 1$-IR neurons and that the majority of ER $\alpha$-IR neurons are unmyelinated. These detailed analyses revealed a clear difference between bladder sensory neurons at different spinal levels, with $\mathrm{ER} \alpha$ only expressed by GFR $\alpha$ 3-IR bladder neurons in the lumbar but not sacral cord. It will be interesting to determine how estrogen exposure influences the function of these different classes of bladder sensory neurons.

Our use of two different $\mathrm{ER} \alpha$ antibodies raises questions about the nature of the antigen that is being revealed. We found a clear overlap in the population of bladder sensory neurons identified by each antibody, but the reagent from Millipore labeled many fewer neurons and specifically failed to label the peptidergic class (Kiasalari et al., 2010). It is possible that a particular isoform of the receptor is not expressed by these neurons. Other possible explanations for this discrepancy suggested by a previous study in rats (Kiasalari et al., 2010) include: the bladder afferents may have a distinct ER phenotype compared with perineal afferents analyzed in the previous study; the earlier study used male Wistar rats whereas we used female Sprague-Dawley rats; we used direct labeling using fluorophore conjugated secondary antibodies whereas the previous study used tyramide amplification in conjunction with the Millipore antibody.

Our immunohistochemical approach also allowed us to distinguish between myelinated and unmyelinated neurons. Consistent with previous studies (Yoshimura et al., 1998; Hayashi et al., 2009; Russo et al., 2013), we found that over half of all bladder afferent neurons contained NF200-IR. We predict that these are the A $\delta$ mechanosensitive neurons with thinly myelinated axons (Lawson et al., 1993). These neurons are likely to respond to innocuous stimuli such as normal levels of bladder distension. This is the first study to define which chemical classes of bladder afferent neurons are myelinated. Our results indicate that most of the neuronal types examined in this study comprise a mixture of myelinated and unmyelinated afferents. The prevalence of myelinated neurons in each group was similar in lumbar and sacral bladder afferents, with the exception of ER $\alpha$-IR neurons, where a higher proportion of these were myelinated in sacral than lumbar neurons.

In this study, we identified a number of immunohistochemical differences between lumbar and sacral bladder afferents. It would be very interesting to determine how these relate to functional differences. Lumbar and sacral components of bladder sensory afferents have been previously been distinguished in a number of ways. Most obviously, sacral but not lumbar afferents are required for the micturition reflex, and undergo major changes during inflammation that are thought to contribute to bladder symptoms and pain (Yoshimura et al., 2002; Fowler et al., 2008; De Groat and Yoshimura, 2009). However, lumbar bladder afferents also become sensitized with inflammation (Mitsui et al., 2001). Moreover, it has been demonstrated in the mouse that lumbar and sacral bladder afferents terminate in different tissues within the bladder and can be activated with different stimuli (Xu and Gebhart, 2008). A similar body of information does not yet exist for the rat bladder, but it would be interesting to define the sources of termination within the bladder wall of each neuronal population studied here. At present there are no unique markers for these spatially distinct groups of axons.

In the current study, we utilized ATF-3 expression to identify populations of bladder afferent neurons that were likely to be injured and undergoing structural remodeling during acute bladder inflammation. These were observed only in sacral DRG, where they comprised a minor class $(<10 \%)$ of bladder afferent neurons. The absence of ATF-3 from lumbar DRG may indicate that these neurons do not change in response to CYP or that their terminals are more distant from the remodeling urothelium. We chose ATF-3 for this study on the basis of a previous study that observed ATF-3 induction in sensory neurons following injection of noxious irritants into the hindpaw (Braz and Basbaum, 2010). Our result is also consistent with reports of ATF-3 induction in lumbar DRGs by mono-iodoacetate-induced osteoarthritis (Ivanavicius et al., 2007), a model of joint in inflammation that produces concurrent axonal damage required to drive ATF-3 induction. In our study, a possible explanation for the ATF3 induction is that CYP metabolism to acrolein causes a rapid destruction of the urothelium, allowing toxic substances in urine to impact on the activity and structure of suburothelial axons. These axons could potentially be sensitized and contribute to altered reflex behaviors during inflammation. However, it should be noted that CYP has additional properties and systemic effects (e.g., immunosuppression) that were not examined in this study and could contribute to our results. Nevertheless, the acuteness of the ATF-3 upregulation and its typical association with neuronal injury, provide strong support for involvement of a bladder-related mechanism, such as urothelial damage.

We also found that acute CYP induced an increase in NOS expression in some sacral (but not lumbar) bladder afferents. This raises the possibility that NOS upregulation is occurring in the ATF-3-IR neurons. Rapid up-regulation of NOS in DRGs has been reported previously following CYP (Vizzard et al., 1996) or intra-vesical mustard oil (Callsen-Cencic and Mense, 1997). Nitrergic activity in the spinal cord has been implicated in bladder hyperactivity following acute inflammation (Kakizaki and De Groat, 1996), but peripheral actions of increased nitric 
oxide synthesis should also be considered. Our results are also consistent with an increase of calcium-dependent NOS activity in spinal cord in association with CYP-induced bladder hyperreflexia (Lagos and Ballejo, 2004). We did not see an acute effect of CYP treatment on expression of other neuronal markers (CGRP, GFRs) but it should be recognized that by assessing only the proportion of neurons expressing a certain substance, we may fail to see smaller changes in expression. Moreover, we did not assess neuronal size, which could have potentially been altered by inflammation and, if changing, confound our sampling of neurons for quantitation.

In conclusion, we have defined for the first time the bladder sensory neurons that express receptors for GDNF, artemin, and estrogens. We have also provided a detailed characterization of myelinated bladder afferents. The complexity and heterogeneity of bladder sensory neurons is reflected at both lumbar and sacral levels but not identical in each. Our study has also identified a sub-population of NOS-IR sacral sensory neurons that are likely to be undergoing structural remodeling during acute inflammation of the bladder. Together these results contribute to increased understanding of the neurons that are known to be involved in pain modulation and hyperreflexia during inflammation.

\section{AUTHOR CONTRIBUTIONS}

Shelley L. Forrest conducted all of the experimental work and participated in drafting the manuscript. Peregrine B. Osborne and Janet R. Keast conceived the study, participated in data analysis, and took primary responsibility for drafting the manuscript.

\section{ACKNOWLEDGMENTS}

This study was supported by Award Number R01DK069351 from the National Institute of Diabetes and Digestive and Kidney Diseases (NIDDK). The content is solely the responsibility of the authors and does not necessarily represent the official views of the NIDDK or the National Institutes of Health. It was also supported by Project Grant 1003512 and Senior Research Fellowship 632903 from the National Health and Medical Research Council of Australia.

\section{REFERENCES}

Avelino, A., Charrua, A., Frias, B., Cruz, C., Boudes, M., De Ridder, D., et al. (2013). Transient receptor potential channels in bladder function. Acta Physiol. 207, 110-122. doi: 10.1111/apha.12021

Averill, S., Mcmahon, S. B., Clary, D. O., Reichardt, L. F., and Priestley, J. V. (1995). Immunocytochemical localization of trkA receptors in chemically identified subgroups of adult rat sensory neurons. Eur. J. Neurosci. 7, 1484-1494. doi: 10.1111/j.1460-9568.1995.tb01143.x

Averill, S., Michael, G. J., Shortland, P. J., Leavesley, R. C., King, V. R., Bradbury, E. J., et al. (2004). NGF and GDNF ameliorate the increase in ATF3 expression which occurs in dorsal root ganglion cells in response to peripheral nerve injury. Eur. J. Neurosci. 19, 1437-1445. doi: 10.1111/j.1460-9568.2004.03241.x

Bennett, D. L., Boucher, T. J., Armanini, M. P., Poulsen, K. T., Michael, G. J., Priestley, J. V., et al. (2000). The glial cell line-derived neurotrophic factor family receptor components are differentially regulated within sensory neurons after nerve injury. J. Neurosci. 20, 427-437.

Bennett, D. L. H., Michael, G. J., Ramachandran, N., Munson, J. B., Averill, S., Yan, Q., et al. (1998). A distinct subgroup of small DRG cells express GDNF receptor components and GDNF is protective for these neurons after nerve injury. J. Neurosci. 18, 3059-3072.

Bennett, H. L., Gustafsson, J. A., and Keast, J. R. (2003). Estrogen receptor expression in lumbosacral dorsal root ganglion cells innervating the female rat urinary bladder. Auton. Neurosci. 105, 90-100. doi: 10.1016/S1566-0702(03) 00044-4

Bespalov, M. M., and Saarma, M. (2007). GDNF family receptor complexes are emerging drug targets. Trends Pharmacol. Sci. 28, 68-74. doi: 10.1016/j.tips.2006.12.005

Birder, L. A. (2011). Urothelial signaling. Handb. Exp. Pharmacol. 202, 207-231. doi: 10.1007/978-3-642-16499-6_10

Birder, L. A., Ruggieri, M., Takeda, M., Van Koeveringe, G., Veltkamp, S., Korstanje, C., et al. (2012). How does the urothelium affect bladder function in health and disease? ICI-RS 2011. Neurourol Urodyn. 31, 293-299. doi: 10.1002/nau.22195

Bjorling, D. E., Beckman, M., and Saban, R. (2003). Neurogenic inflammation of the bladder. Adv. Exp. Med. Biol. 539, 551-583. doi: 10.1007/978-1-4419-88898_37

Braz, J. M., and Basbaum, A. I. (2010). Differential ATF3 expression in dorsal root ganglion neurons reveals the profile of primary afferents engaged by diverse noxious chemical stimuli. Pain 150, 290-301. doi: 10.1016/j.pain.2010.05.005

Callsen-Cencic, P., and Mense, S. (1997). Expression of neuropeptides and nitric oxide synthase in neurones innervating the inflamed rat urinary bladder. J. Auton. Nerv. Syst. 65, 33-44. doi: 10.1016/S0165-1838(97)00032-5

Cheng, Y., and Keast, J. R. (2009). Effects of estrogens and bladder inflammation on mitogen-activated protein kinases in lumbosacral dorsal root ganglia from adult female rats. BMC Neurosci. 10:156. doi: 10.1186/1471-2202-10-156

Corrow, K. A., and Vizzard, M. A. (2007). Phosphorylation of extracellular signalregulated kinases (pERK) in urinary bladder in rats with Cyclophosphamide (CYP)-induced cystitis. Am. J. Physiol. Regul. Integr. Comp. Physiol. 293, R125-R134. doi: 10.1152/ajpregu.00857.2006

Cox, P. J. (1979). Cyclophosphamide cystitis-identification of acrolein as the causative agent. Biochem. Pharmacol. 28, 2045-2049. doi: 10.1016/00062952(79)90222-3

Daly, D. M., Collins, V. M., Chapple, C. R., and Grundy, D. (2011). The afferent system and its role in lower urinary tract dysfunction. Curr. Opin. Urol. 21, 268-274. doi: 10.1097/MOU.0b013e3283476ea2

De Groat, W. C., and Yoshimura, N. (2001). Pharmacology of the lower urinary tract. Annu. Rev. Pharmacol. Toxicol. 41, 691-721. doi: 10.1146/annurev.pharmtox.41.1.691

De Groat, W. C., and Yoshimura, N. (2009). Afferent nerve regulation of bladder function in health and disease. Handb. Exp. Pharmacol. 194, 91-138. doi: 10.1007/978-3-540-79090-7_4

Dmitrieva, N., and Berkley, K. J. (2005). Influence of estradiol on micturition thresholds in the rat: involvement of the hypogastric nerve. Am. J. Physiol. Regul. Integr. Comp. Physiol. 289, R1724-R1728. doi: 10.1152/ajpregu.00468.2005

Dmitrieva, N., Shelton, D., Rice, A. S., and Mcmahon, S. B. (1997). The role of nerve growth factor in a model of visceral inflammation. Neuroscience 78, 449-459. doi: 10.1016/S0306-4522(96)00575-1

Elitt, C. M., Mcilwrath, S. L., Lawson, J. J., Malin, S. A., Molliver, D. C., Cornuet, P. K., et al. (2006). Artemin overexpression in skin enhances expression of TRPV1 and TRPA1 in cutaneous sensory neurons and leads to behavioral sensitivity to heat and cold. J. Neurosci. 26, 8578-8587. doi: 10.1523/JNEUROSCI.218506.2006

Ernsberger, U. (2008). The role of GDNF family ligand signalling in the differentiation of sympathetic and dorsal root ganglion neurons. Cell Tissue Res. 333, 353-371. doi: 10.1007/s00441-008-0634-4

Forrest, S. L., and Keast, J. R. (2008). Expression of receptors for glial cell line-derived neurotrophic factor family ligands in sacral spinal cord reveals separate targets of pelvic afferent fibers. J. Comp. Neurol. 506, 989-1002. doi: $10.1002 / \mathrm{cne} .21535$

Fowler, C. J., Griffiths, D., and De Groat, W. C. (2008). The neural control of micturition. Nat. Rev. Neurosci. 9, 453-466. doi: 10.1038/nrn2401

Gintzler, A. R., and Liu, N. J. (2012). Importance of sex to pain and its amelioration; relevance of spinal estrogens and its membrane receptors. Front. Neuroendocrinol. 33:412-424. doi: 10.1016/j.yfrne.2012.09.004

Hai, T., Wolfgang, C. D., Marsee, D. K., Allen, A. E., and Sivaprasad, U. (1999). ATF3 and stress responses. Gene Expr. 7, 321-335.

Hayashi, T., Kondo, T., Ishimatsu, M., Yamada, S., Nakamura, K., Matsuoka, K., et al. (2009). Expression of the TRPM8-immunoreactivity in dorsal root ganglion neurons innervating the rat urinary bladder. Neurosci. Res. 65, 245-251. doi: 10.1016/j.neures.2009.07.005

Ivanavicius, S. P., Ball, A. D., Heapy, C. G., Westwood, F. R., Murray, F., and Read, S. J. (2007). Structural pathology in a rodent model of osteoarthritis is associated 
with neuropathic pain: increased expression of ATF-3 and pharmacological characterisation. Pain 128, 272-282. doi: 10.1016/j.pain.2006.12.022

Johnson, O. L., and Berkley, K. J. (2002). Estrous influences on micturition thresholds of the female rat before and after bladder inflammation. Am. J. Physiol. Regul Integr Comp Physiol. 282, R289-R294.

Julius, D., and Basbaum, A. I. (2001). Molecular mechanisms of nociception. Nature 413, 203-210. doi: 10.1038/35093019

Kakizaki, H., and De Groat, W. C. (1996). Role of spinal nitric oxide in the facilitation of the micturition reflex by bladder irritation. J. Urol. 155, 355-360. doi: 10.1016/S0022-5347(01)66660-6

Kalous, A., Osborne, P. B., and Keast, J. R. (2007). Acute and chronic changes in dorsal horn innervation by primary afferents and descending supraspinal pathways after spinal cord injury. J. Comp. Neurol. 504, 238-253. doi: $10.1002 /$ cne. 21412

Kalous, A., Osborne, P. B., and Keast, J. R. (2009). Spinal cord compression injury in adult rats initiates changes in dorsal horn remodeling that may correlate with development of neuropathic pain. J. Comp. Neurol. 513, 668-684. doi: $10.1002 / \mathrm{cne} .21986$

Kanai, A. J. (2011). Afferent mechanism in the urinary tract. Handb. Exp. Pharmacol. 202, 171-205. doi: 10.1007/978-3-642-16499-6_9

Keast, J. R., and De Groat, W. C. (1992). Segmental distribution and peptide content of primary afferent neurons innervating the urogenital organs and colon of male rats. J. Comp. Neurol. 319, 615-623. doi: 10.1002/cne.903190411

Kiasalari, Z., Salehi, I., Zhong, Y., Mcmahon, S. B., Michael-Titus, A. T., and Michael, G. J. (2010). Identification of perineal sensory neurons activated by innocuous heat. J. Comp. Neurol. 518, 137-162. doi: 10.1002/cne.22187

Lagos, P., and Ballejo, G. (2004). Role of spinal nitric oxide synthasedependent processes in the initiation of the micturition hyperreflexia associated with cyclophosphamide-induced cystitis. Neuroscience 125, 663-670. doi: 10.1016/j.neuroscience.2003.10.048

Laurikainen, A., Hiltunen, J. O., Thomas-Crussells, J., Vanhatalo, S., Arumäe, U., Airaksinen, M. S., et al. (2000). Neurturin is a neurotrophic factor for penile parasympathetic neurons in adult rat. J. Neurobiol. 43, 198-205. doi: 10.1002/(SICI) 1097-4695(200005)43:2 < 198::AID-NEU9>3.0.CO;2-D

Lawson, S. N., Crepps, B. A., and Perl, E. R. (1997). Relationship of substance P to afferent characteristics of dorsal root ganglion neurones in guinea-pig. J. Physiol. 505(pt 1), 177-191. doi: 10.1111/j.1469-7793.1997.00177.x

Lawson, S. N., Perry, M. J., Prabhakar, E., and Mccarthy, P. W. (1993). Primary sensory neurones: neurofilament, neuropeptides, and conduction velocity. Brain Res. Bull. 30, 239-243. doi: 10.1016/0361-9230(93)90250-F

Lindfors, P. H., Voikar, V., Rossi, J., and Airaksinen, M. S. (2006). Deficient nonpeptidergic epidermis innervation and reduced inflammatory pain in glial cell line-derived neurotrophic factor family receptor alpha2 knock-out mice. J. Neurosci. 26, 1953-1960. doi: 10.1523/JNEUROSCI.4065-05.2006

Maggi, C. A. (1992). Therapeutic potential of capsaicin-like molecules: studies in animals and humans. Life Sci. 51, 1777-1781. doi: 10.1016/00243205(92)90047-S

Maggi, C. A., Lecci, A., Santicioli, P., Del Bianco, E., and Giuliani, S. (1992). Cyclophosphamide cystitis in rats: involvement of capsaicin-sensitive primary afferents. J. Auton. Nerv. Syst. 38, 201-208. doi: 10.1016/0165-1838(92)90031-B

Malin, S., Molliver, D., Christianson, J. A., Schwartz, E. S., Cornuet, P., Albers, K. M., et al. (2011). TRPV1 and TRPAl function and modulation are target tissue dependent. J. Neurosci. 31, 10516-10528. doi: 10.1523/JNEUROSCI.299210.2011

Malin, S. A., Molliver, D. C., Koerber, H. R., Cornuet, P., Frye, R., Albers, K. M., et al. (2006). Glial cell line-derived neurotrophic factor family members sensitize nociceptors in vitro and produce thermal hyperalgesia in vivo. J. Neurosci. 26, 8588-8599. doi: 10.1523/JNEUROSCI.1726-06.2006

Merrill, L., Girard, B., Arms, L., Guertin, P., and Vizzard, M. A. (2013). Neuropeptide/Receptor expression and plasticity in micturition pathways. Curr. Pharm. Des. 19, 4411-4422. doi: 10.2174/1381612811319240008

Mitsui, T., Kakizaki, H., Matsuura, S., Ameda, K., Yoshioka, M., and Koyanagi, T. (2001). Afferent fibers of the hypogastric nerves are involved in the facilitating effects of chemical bladder irritation in rats. J. Neurophysiol. 86, 2276-2284.

Nazif, O., Teichman, J. M., and Gebhart, G. F. (2007). Neural upregulation in interstitial cystitis. Urology 69, 24-33. doi: 10.1016/j.urology.2006.08.1108

Orozco, O. E., Walus, L., Sah, D. W., Pepinsky, R. B., and Sanicola, M. (2001). GFRalpha3 is expressed predominantly in nociceptive sensory neurons. Eur. J. Neurosci. 13, 2177-2182. doi: 10.1046/j.0953-816x.2001.01596.x
Pezet, S., and Mcmahon, S. B. (2006). Neurotrophins: mediators and modulators of pain. Annu. Rev. Neurosci. 29, 507-538. doi: 10.1146/annurev.neuro.29.051605.112929

Robbins, A., Berkley, K. J., and Sato, Y. (1992). Estrous cycle variation of afferent fibers supplying reproductive organs in the female rat. Brain Res. 596, 353-356. doi: 10.1016/0006-8993(92)91572-V

Robbins, A., Sato, Y., Hotta, J., and Berkeley, K. J. (1990). Responses of hypogastric nerve afferent fibers to uterine distension in estrous or metestrous rats. Neurosci. Lett. 110, 82-85. doi: 10.1016/0304-3940(90)90791-7

Robinson, D., and Cardozo, L. D. (2003). The role of estrogens in female lower urinary tract dysfunction. Urology 62(Suppl. 1), 45-51. doi: 10.1016/S00904295(03)00676-9

Robinson, D. R., and Gebhart, G. F. (2008). Inside information: the unique features of visceral sensation. Mol. Interv. 8, 242-253. doi: 10.1124/mi.8.5.9

Russo, D., Clavenzani, P., Sorteni, C., Bo Minelli, L., Botti, M., Gazza, F., et al. (2013). Neurochemical features of boar lumbosacral dorsal root ganglion neurons and characterization of sensory neurons innervating the urinary bladder trigone. J. Comp. Neurol. 521, 342-366. doi: 10.1002/cne.23177

Sanoja, R., and Cervero, F. (2005). Estrogen-dependent abdominal hyperalgesia induced by ovariectomy in adult mice: a model of functional abdominal pain. Pain 118, 243-253. doi: 10.1016/j.pain.2005.08.021

Seijffers, R., Mills, C. D., and Woolf, C. J. (2007). ATF3 increases the intrinsic growth state of DRG neurons to enhance peripheral nerve regeneration. J. Neurosci. 27, 7911-7920. doi: 10.1523/JNEUROSCI.5313-06.2007

Sengupta, J. N., and Gebhart, G. F. (1994). Mechanosensitive properties of pelvic nerve afferent fibers innervating the urinary bladder of the rat. J. Neurophysiol. 72, 2420-2430.

Shea, V. K., Cai, R., Crepps, B., Mason, J. L., and Perl, E. R. (2000). Sensory fibers of the pelvic nerve innervating the Rat's urinary bladder. J. Neurophysiol. 84, 1924-1933.

Shortland, P. J., Baytug, B., Krzyzanowska, A., Mcmahon, S. B., Priestley, J. V., and Averill, S. (2006). ATF3 expression in L4 dorsal root ganglion neurons after L5 spinal nerve transection. Eur. J. Neurosci. 23, 365-373. doi: 10.1111/j.14609568.2005.04568.x

Skryma, R., Prevarskaya, N., Gkika, D., and Shuba, Y. (2011). From urgency to frequency: facts and controversies of TRPs in the lower urinary tract. Nat. Rev. Urol. 8, 617-630. doi: 10.1038/nrurol.2011.142

Stucky, C. L., Rossi, J., Airaksinen, M. S., and Lewin, G. R. (2002). GFRa2/neurturin signalling regulates noxious heat transduction in isolectin $\mathrm{B}_{4}$-binding mouse sensory neurons. J. Physiol. 545, 43-50. doi: 10.1113/jphysiol.2002. 027656

Tanaka, T., Shinoda, M., Feng, B., Albers, K. M., and Gebhart, G. F. (2011). Modulation of visceral hypersensitivity by glial cell line-derived neurotrophic factor family receptor andalpha;-3 in colorectal afferents. Am. J. Physiol. Gastrointest. Liver Physiol. 300, G418-G424. doi: 10.1152/ajpgi. 00456.2010

Tsujino, H., Kondon, E., Fukuoka, T., Dai, Y., Tokunaga, A., Miki, K., et al. (2000). Activating transcription factor 3 (ATF3) induction by axotomy in sensory and motoneurons: a novel neuronal marker of nerve injury. Mol. Cell. Neurosci. 15, 170-182. doi: 10.1006/mcne.1999.0814

Vizzard, M. A. (2000). Changes in urinary bladder neurotrophic factor mRNA and NGF protein following urinary bladder dysfunction. Exp. Neurol. 161, 273-284. doi: 10.1006/exnr.1999.7254

Vizzard, M. A. (2001). Alterations in neuropeptide expression in lumbosacral bladder pathways following chronic cystitis. J. Chem. Neuroanat. 21, 125-138. doi: 10.1016/S0891-0618(00)00115-0

Vizzard, M. A., Erdman, S. L., and De Groat, W. C. (1995a). Increased expression of neuronal nitric oxide synthase (NOS) in visceral neurons after nerve injury. J. Neurosci. 15, 4033-4045.

Vizzard, M. A., Erdman, S. L., and De Groat, W. C. (1995b). Increased expression of neuronal nitric oxide synthase in dorsal root ganglion neurons after systemic capsaicin administration. Neuroscience 67, 1-5. doi: 10.1016/03064522(95)00137-8

Vizzard, M. A., Erdman, S. L., and De Groat, W. C. (1996). Increased expression of neuronal nitric oxide synthase in bladder afferent pathways following chronic bladder irritation. J. Comp. Neurol. 370, 191-202. doi: 10.1002/(SICI)10969861(19960624)370:2<191::AID-CnE5>3.0.co;2-Y

Wanigasekara, Y., Airaksinen, M. S., Heuckeroth, R. O., Milbrandt, J., and Keast, J. R. (2004). Neurturin signalling via GFRalpha2 is essential for innervation of 
glandular but not muscle targets of sacral parasympathetic ganglion neurons. Mol. Cell. Neurosci. 25, 288-300. doi: 10.1016/j.mcn.2003.10.019

Wanigasekara, Y., and Keast, J. R. (2005). Neurturin has multiple neurotrophic effects on adult rat sacral parasympathetic ganglion neurons. Eur. J. Neurosci. 22, 595-604. doi: 10.1111/j.1460-9568.2005.04260.x

Warren, J. W., Clauw, D. J., Wesselmann, U., Langenberg, P. W., Howard, F. M., and Morozov, V. (2011). Sexuality and reproductive risk factors for interstitial cystitis/painful bladder syndrome in women. Urology 77, 570-575. doi: 10.1016/j.urology.2010.10.018

$\mathrm{Xu}$, A., Frederiksen, H., Kanje, M., and Uvelius, B. (2011). Partial urethral obstruction: ATF3 and p-c-Jun are involved in the growth of the detrusor muscle and its motor innervation. Scand. J. Urol. Nephrol. 45, 30-38. doi: $10.3109 / 00365599.2010 .521188$

$\mathrm{Xu}, \mathrm{L}$., and Gebhart, G. F. (2008). Characterization of mouse lumbar splanchnic and pelvic nerve urinary bladder mechanosensory afferents. J. Neurophysiol. 99, 244-253. doi: 10.1152/jn.01049.2007

$\mathrm{Xu}$, S., Cheng, Y., Keast, J. R., and Osborne, P. B. (2008). 17beta-estradiol activates estrogen receptor beta-signalling and inhibits transient receptor potential vanilloid receptor 1 activation by capsaicin in adult rat nociceptor neurons. Endocrinology 149, 5540-5548. doi: 10.1210/en.2008-0278

Yoshimura, N., Erdman, S. L., Snider, M. W., and De Groat, W. C. (1998). Effects of spinal cord injury on neurofilament immunoreactivity and capsaicin sensitivity in rat dorsal root ganglion neurons innervating the urinary bladder. Neuroscience 83, 633-643. doi: 10.1016/S0306-4522(97) 00376-X

Yoshimura, N., Seki, S., Chancellor, M. B., De Groat, W. C., and Ueda, T. (2002). Targeting afferent hyperexcitability for therapy of the painful bladder syndrome. Urology 59, 61-67. doi: 10.1016/S0090-4295(01) 01639-9

Yoshimura, N., Seki, S., Erickson, K. A., Erickson, V. L., Hancellor, M. B., and De Groat, W. C. (2003). Histological and electrical properties of rat dorsal root ganglion neurons innervating the lower urinary tract. J. Neurosci. 23, 4355-4361.

Conflict of Interest Statement: The authors declare that the research was conducted in the absence of any commercial or financial relationships that could be construed as a potential conflict of interest.

Received: 18 September 2013; accepted: 16 October 2013; published online: 07 November 2013.

Citation: Forrest SL, Osborne PB and Keast JR (2013) Characterization of bladder sensory neurons in the context of myelination, receptors for pain modulators, and acute responses to bladder inflammation. Front. Neurosci. 7:206. doi: 10.3389/fnins. 2013.00206

This article was submitted to Autonomic Neuroscience, a section of the journal Frontiers in Neuroscience.

Copyright (C) 2013 Forrest, Osborne and Keast. This is an open-access article distributed under the terms of the Creative Commons Attribution License (CC BY). The use, distribution or reproduction in other forums is permitted, provided the original author(s) or licensor are credited and that the original publication in this journal is cited, in accordance with accepted academic practice. No use, distribution or reproduction is permitted which does not comply with these terms. 